\title{
The IAEA standards for the radioactive discharge control: Present status and future development
}

\author{
M. Balonov, G. Linsley, D. Louvat, C. Robinson and T. Cabianca \\ International Atomic Energy Agency, Wagramer Strasse 5, PO Box 100, Vienna, Austria
}

\begin{abstract}
As part of its functions, the IAEA periodically reviews the status and continued relevance of the safety standards to the needs of its Member States. Recent work is described on the development of standards for the radioactive discharge control including the development of practical guidance for setting discharge limits, the elaboration of a methodology for the radiation protection of non-human species, and the preparation of guidance on environmental modeling and monitoring for radiation protection purposes. The development of the IAEA safety documents is influenced both by the new ICRP recommendations and feedback from practical experience of application of existing standards. Recent international and regional tendencies, to reduce radioactive discharges below levels justified by radiological criteria are discussed.
\end{abstract}

\section{INTRODUCTION}

The International Atomic Energy Agency (IAEA) is the organization within the United Nations family with a statutory mandate to establish standards for the protection of health and environment against ionizing radiation, and to provide for the application of those standards. As part of these functions, the IAEA periodically reviews the status and continued relevance of the safety standards to the needs of its Member States.

Recent work on the development of standards for the radioactive discharge control includes the development of practical guidance for setting discharge limits, the elaboration of a methodology for protection of non-human species (biota), and the preparation of guidance on environmental monitoring for radiation protection purposes. The development of these safety documents is based on relevant scientific reports of the United Nations Scientific Committee on the Effects of Atomic Radiation [1] and the recommendations of the International Commission on Radiological Protection (ICRP). This work is also influenced by recent international and regional trends, towards reducing radioactive discharges substantially below levels justified by radiological criteria.

\section{PRESENT INTERNATIONAL GUIDANCE}

\subsection{Radiological criteria of the ICRP}

Amongst the ICRP recommendations issued after 1990, when substantial changes in the general philosophy of radiation protection occurred, the issues of environmental radioactivity and relevant protection of the public and the environment have been considered mainly in Recommendations 60 and 91 [2, 3].

ICRP Publication 60 [2] recommends justifying necessary measures for protection of the public in practice situations via constrained optimization procedures. Whereas public annual effective dose limit from all controllable environmental radiation sources (except of natural background) was established equal to $1 \mathrm{mSv}$, the constraint value relevant to a single source should be a non-specified fraction of this limit. Both the dose limit and constraint apply to representatives of the highest exposed members of the public (the critical group) in the radiation conditions under consideration. 


\subsection{IAEA safety standards and reports}

The IAEA safety standards are organized in three levels: Safety Fundamentals (upper level), Safety Requirements and Safety Guides. The system of IAEA standards and supporting reports relevant to radioactive discharge control is presented in Figure 1.

\begin{tabular}{|c|}
\hline Fundamentals \\
\hline $\begin{array}{c}\text { The Principles } \\
\text { of Radioactive } \\
\text { Waste } \\
\text { Management }\end{array}$ \\
\hline
\end{tabular}

Requirements

\begin{tabular}{|c|}
\hline International Basic \\
Safety Standards \\
for Protection \\
Against Ionizing \\
Radiation \\
\hline
\end{tabular}

Guides
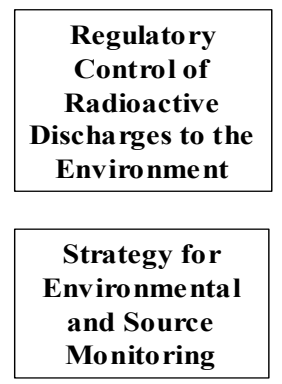

Reports

\begin{tabular}{|l|}
\hline \begin{tabular}{l} 
Generic Models \\
for Use in \\
Assessing the \\
Impact of \\
Radioactive \\
Discharges, SR-19 \\
\hline
\end{tabular} Monitoring and \\
Surveillance of \\
Residues from the \\
Mining and \\
Milling, SR-27 \\
\hline $\begin{array}{l}\text { Surveillance and } \\
\text { Monitoring of } \\
\text { Near Surface } \\
\text { Disposal Facilities } \\
\text { for Radioactive } \\
\text { Waste, SR-35 }\end{array}$ \\
\hline
\end{tabular}

Figure 1. The IAEA safety documents in the area of discharge control.

According to the relevant Safety Fundamentals entitled The Principles of Radioactive Waste Management [5], "The objective of radioactive waste management is to deal with radioactive waste in a manner that protects human health and the environment now and in the future without imposing undue burdens on future generations." They also contain specific requirements to provide for the safety of the public and the environment beyond national borders and for safety of future generations.

Within the Safety Requirements, the issues of discharge control are considered mainly in the Basic Safety Standards [5], which converted ICRP recommendations on radiation protection of members of the public [2] into the international safety standard form. The general requirement is that "Registrants and licensees shall ensure that radioactive substances from authorized practices and sources not be discharged to the environment unless:

(a) the discharge is within the discharge limits authorized by the Regulatory Authority;

(b) the discharges are controlled;

(c) the public exposures committed by the discharges are limited as specified in $([2,5])$...; and

(d) the control of the discharges is optimized in accordance with the Principal Requirements of the Standards."

The Safety Guide on Regulatory Control of Radioactive Discharges to the Environment [6] contains very detailed guidance on public safety associated with radioactive discharges. It establishes the responsibilities of the Regulatory Body and operators (registrants and licensees) for public protection. Table 1 provides a summary of the procedures of notification, registration or licensing that should be applied before practices are introduced, depending on the activities of radionuclides and technologies used as well as actual and potential discharges.

The documents submitted by the facility administration to the Regulatory Body should prove that: 1) annual doses to the public (critical group) are below dose constraints; 2) protection is optimized. In the Guide, the experience of numerous countries in establishing dose constraints has been reviewed; the values are mainly between 0.1 and $0.3 \mathrm{mSv}$, which can be considered a relatively narrow range. Based on this analysis the Guide [6] recommends that as a rule the annual dose constraint should not exceed $0.3 \mathrm{mSv}$. 
Table 1. Summary Guidance on Regulatory Requirements [6].

\begin{tabular}{|c|c|c|c|}
\hline \multirow[b]{3}{*}{$\begin{array}{l}\text { Regulatory } \\
\text { requirements }\end{array}$} & \multicolumn{3}{|c|}{ Assessed future maximum annual dose to the critical group } \\
\hline & \multicolumn{2}{|c|}{$\mathrm{E} \leq 10 \mu \mathrm{Sv}$} & \multirow{2}{*}{$\begin{array}{l}\mathrm{E}>10 \mu \mathrm{Sv} \\
\text { LICENCE }\end{array}$} \\
\hline & $\begin{array}{l}\text { EXEMPTION OR } \\
\text { NOTIFICATION }\end{array}$ & REGISTRATION & \\
\hline $\begin{array}{l}\text { Recommended } \\
\text { conditions }\end{array}$ & $\begin{array}{l}\text { - Source inherently safe } \\
\text { - No requirements on } \\
\text { effluent or environmental } \\
\text { monitoring } \\
\text { - Practice to be kept under } \\
\text { periodic review }\end{array}$ & $\begin{array}{l}\text { - Source not inherently safe } \\
\text { - Discharge limits required } \\
\text { - Effluent monitoring required } \\
\text { - Practice to be kept under } \\
\text { review } \\
\text { - Recording of discharges } \\
\text { required }\end{array}$ & $\begin{array}{l}\text { Formal authorization with specific } \\
\text { conditions attached to the authorization, } \\
\text { on any or all of the following: } \\
\text { - Discharge limits } \\
\text { - Effluent monitoring } \\
\text { - Environmental monitoring } \\
\text { - Effluent and environmental } \\
\text { monitoring records } \\
\text { - Reporting of monitoring to } \\
\text { regulatory authority }\end{array}$ \\
\hline $\begin{array}{l}\text { Example } \\
\text { facilities }\end{array}$ & $\begin{array}{l}\text { - Research laboratories } \\
\text { using radioimmunoassay } \\
\text { techniques } \\
\text { - Hospitals using xenon } \\
\text { testing kits }\end{array}$ & $\begin{array}{l}\text { - Small hospitals and research } \\
\text { and development facilities } \\
\text { using limited amounts of } \\
\text { radioisotopes }\end{array}$ & $\begin{array}{l}\text { - Nuclear reactors } \\
\text { - Reprocessing facilities } \\
\text { - Radiopharmaceutical production } \\
\text { facilities }\end{array}$ \\
\hline
\end{tabular}

Another relevant Safety Guide is the one on radiation monitoring strategy [7]. Its aim is to establish strategies for radiation monitoring at the source and in the environment coherent with contemporary radiation protection principles. The strategy of monitoring has been developed in relation to control of radionuclide discharges under practice conditions, and intervention, such as in cases of nuclear or radiological emergencies or past contamination of areas with long-lived radionuclides. The Guide is in the final stage of the IAEA approval procedure; its publication is expected in 2005. Practical guidance, both generic and specific to different facilities and situations is being developed in a number of accompanying Safety Reports [8, 9, 10].

All the procedures aiming to establish discharge limitations involve appropriate modeling of radionuclide transfer in the environment and of public exposure. In order to provide for such modeling, the IAEA developed Safety Report No. 19 [8] in 2001, which contains a set of simple up-to-date environmental and dosimetric models as well as sets of necessary default parameters. More detailed data set for transfer in temperate environments can be found in the IAEA Technical Report Series No 364 [11], while appropriate radioecological parameters for the marine environment are available in the recently published Technical Report Series No 422 [12].

Although the calculation procedures needed for practical purposes of discharge control have been provided with up-to-date models and their parameters, radioecological research continues and new data regularly emerge which should be used in modern guidance. It is opportune to mention recent IAEA programmers aimed to refine and validate environmental models.

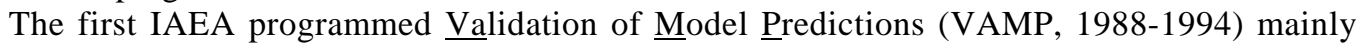
used data sets collected from observations after the Chernobyl accident and resulted in the publication of six IAEA technical documents (TECDOCs) between 1992 and 2000, which contain invaluable radioecological and dosimetric data widely used by modelers. The recently completed Biosphere Modeling and Assessment Programmed (BIOMASS, 1996-2001) significantly contributed to the improvement of modeling in areas of radioactive waste disposal, control of environmental releases and study of biospheric processes. Its findings have been published as seven substantial IAEA reports in 2002-2004.

In 2003, the IAEA launched the latest project in this series, called Environmental Modeling for RAdiation Safety (EMRAS, 2003-2007). Six working groups already operate in the frame of this project aiming to improve/validate models used for assessment of radioactive releases to the atmosphere and water bodies, dose reconstruction for past releases and remediation of areas with radioactive residues. 
Of great importance is the revision of IAEA's Technical Report Series 364 [11] by updating parameter values and extending its scope to other environments, such as tropical and arctic ones. From 2004 the Agency will also establish a working group dealing with biota dose assessment.

\section{CURRENT AND FUTURE DEVELOPMENTS}

\subsection{Changing scene in discharge control}

ICRP is in the process of developing new basic radiation protection recommendations which should be completed and approved in 2005. As far as the subject of this paper, the issues of the public and environment protection, no change to human dose limits for practices is being considered, although biota protection issues will be considered explicitly. More attention will be focused on compliance with dose constraints; detailed ICRP guidance on that is under development. In general, constrained optimization remains the core methodology for establishing the discharge limitations. It is recommended that the optimization process becomes less formal with regard to cost-benefit analysis. More specific assessment of the influence of updated ICRP policy on radioactive discharge control in international context can be done only after publication of the new basic document.

Other new tendencies in discharge control policy have emerged in the context of the Convention for the Protection of the Marine Environment of the North-East Atlantic ("OSPAR Convention") [13] and its Strategy with Regard to Radioactive Substances adopted in 1998. Under that Strategy, “...the objective... is to prevent pollution of the maritime area from ionizing radiation through progressive and substantial reductions of discharges, emissions and losses of radioactive substances, with the ultimate aim of concentrations in the environment near background values for naturally occurring radioactive substances and close to zero for artificial radioactive substances...”.

Although this objective and subsequent OSPAR work programmed from 2003 [14] mentions radiological impacts to man and biota as the issues to be taken into account, in general the concept goes beyond the internationally recognized principle of radiation protection, i.e. optimization, and will result in substantial costs without visible quantifiable benefits. Discussions continue to clarify the meaning of close to zero approach and its relevance to current radiation protection principles [15].

Recent technical meetings held at the IAEA have revealed that national practices of discharge control do not always follow current ICRP and IAEA recommendations based on the formal constrained optimization procedure for a critical group. In a number of countries, instead of a critical group, hypothetical individuals residing at the site boundary are considered as exposure subjects. Both formal cost-benefit analysis (CBA) based on monetary values and more flexible multi-attribute analysis (MAA) accounting both for monetary and qualitative factors are being used worldwide as the optimization techniques. Societal pressures and regulatory practicalities results in discharge controls that were likely to be more restrictive that those that would be implied by formal optimization techniques. More and more best available technique (BAT) oriented rather on technological capabilities than on dose limitations is being used for limiting discharges of radioactive substances. This diversity of national practices is being currently analyzed by the IAEA with the aim to account for it in the safety documents that will be developed.

\subsection{Biota protection}

There is social demand to account for possible harm of radiation for fauna and flora based on ethical principles. Several international organizations, such as ICRP, IAEA, UNSCEAR, International Union of Radioecologists, are currently involved in the development of a system for environmental and specifically biota radiation protection.

The recently published ICRP Publication 91 [3] discussed explicitly the issues of non-human biota protection for the first time and suggested a framework for assessing radiation impact on it. Until the publication of this document ICRP believed "that the standard of environmental control needed to 
protect man to the degree desirable will ensure that other species are not put at risk ...” [2]. Due to recently increased societal interest to this issue, ICRP has launched several new activities among which Publication 91 is just the first step. At present, a special ICRP Task Group is developing recommendations on selection of reference plants and animals and their characteristics for radiological assessment purposes. In 2005, the newly established ICRP Committee 5 is going to address specifically the biota protection issues.

The IAEA has, in recent years, established a program of work specifically addressing the development of safety standards for non-human species, in co-operation with other relevant international organizations. Thus, from 2001 the IAEA organized three major international meetings [15-17] where ethical, methodological and technical aspects of biota protection were discussed, and produced two TECDOCs on this subject $[18,19]$.

The primary objective of the recent International Conference on the Protection of the Environment from the Effects of Ionizing Radiation held in Stockholm in October 2003 was to promote the development of a coherent international policy on the protection of the environment from effects attributable to ionizing radiation exposure. Participants included senior policy makers and technical experts from a wide range of backgrounds, which was necessary to reflect all interests in environmental assessment and management. The Conference concluded that "while accepting that there remain significant gaps in knowledge and that there needs to be continuing research ... there was an adequate knowledge base to proceed and (the Conference) strongly supported the development of a framework for environmental radiation protection". It also found that "the time is ripe for launching a number of international initiatives to consolidate the present approach to controlling radioactive discharges to the environment by taking explicit account of the protection of species other than humans".

Based on the findings and recommendations of the Stockholm Conference, the IAEA is currently developing an International Action Plan on the protection of the environment from the effects of ionizing radiation with the main focus on the possible form of future regulatory criteria, the application of biota effect data, and their relationship to discharge regulation.

\subsection{Update of IAEA discharge regulation}

Currently, the IAEA is reviewing its system of safety standards in order to make it more effective for Member States. As a result it is possible that existing documents and those being currently developed will be combined, or rearranged Therefore, it is difficult to predict the precise form of future safety standards. However, it is expected that the following safety standards will be modified in the next 2 to 5 years as follows:

Safety Fundamentals - the current document [4] covers fundamentals of both public and environmental protection. However, this document is planned to be combined with other Safety Fundamentals.

Safety Requirements - modification of BSS [5] based on the new ICRP recommendations and development of specific Safety Requirements on radioactive waste management is expected.

Safety Guides - update of WS-G-2.3 [6] is planned to include explicitly safety considerations for both the public and the environment, as well as to take account of the realities of setting discharge limits and of the new basic ICRP recommendations.

The application of these safety standards by IAEA Member States is expected to create a demand for a development of appropriate supporting technical documents (Safety Reports, Technical Reports Series, TECDOCs), such as:

- $\quad$ Practical aspects of setting discharge limits;

- $\quad$ Update of TRS-364 [11];

- Facility-specific source and environmental monitoring;

- Environmental assessment methodologies, and some others. 
In conclusion from this review it is evident that the IAEA standards for radioactive discharge control are developing in accordance with both the development of modern radiation protection policies and feedback from practical experience of application of existing standards. Recent international and regional trends, towards reducing radioactive discharges below levels justified by radiological criteria remain under discussion. According to current planning, a comprehensive set of appropriate IAEA safety documents concerning protection of the public and the environment against environmental radioactivity will be completed tentatively by $2008-2010$.

\section{References}

[1] United Nations Scientific Committee on the Effects of Atomic Radiation, Sources and Effects of Ionizing Radiation (2000 Report to the General Assembly), UN, New York (2000) Volume I.

[2] International Commission on Radiological Protection, 1990 Recommendations of the International Commission on Radiological Protection, ICRP Publication 60, Pergamon Press, Oxford and New York (1991).

[3] International Commission on Radiological Protection, A Framework for Assessing the Impact of Ionizing Radiation on Non-human Species. ICRP Publication No. 91, Annals of the ICRP, Vol. 33, No. 3, (2003).

[4] International Atomic Energy Agency, The Principles of Radioactive Waste Management. Safety Series No 111-F, IAEA, Vienna (1995).

[5] International Atomic Energy Agency, International Basic Safety Standards for Protection Against Ionizing Radiation and for the Safety of Radiation Sources, Safety Series No. 115, IAEA, Vienna (1996).

[6] International Atomic Energy Agency, Regulatory Control of Radioactive Discharges to the Environment, Safety Standards Series No. WS-G-2.3, IAEA, Vienna (2000).

[7] International Atomic Energy Agency, Strategy for Environmental and Source Monitoring for Public Protection Purposes (DS62), IAEA, to be published.

[8] International Atomic Energy Agency, Generic Models for Use in Assessing the Impact of Discharges of Radioactive Substances to the Environment, Safety Reports Series No. 19, IAEA, Vienna (2001).

[9] International Atomic Energy Agency, Monitoring and Surveillance of Residues from the Mining and Milling of Uranium and Thorium, Safety Reports Series No. 27, IAEA, Vienna (2003).

[10] International Atomic Energy Agency, Surveillance and Monitoring of Near Surface Disposal Facilities for Radioactive Waste, Safety Reports Series No. 35, IAEA, Vienna (2004).

[11] International Atomic Energy Agency, Handbook of Parameter Values for the Prediction of Radionuclide Transfer in Temperate Environments, Technical Reports Series No. 364, IAEA, Vienna (1994).

[12] International Atomic Energy Agency, Sediment Distribution Coefficients and Concentration Factors for Biota in the Marine Environment, Technical Reports Series No. 422, IAEA, Vienna (2004).

[13] OSPAR Convention for the Protection of the Marine Environment of the North-East Atlantic (1996).

[14] http://www.ospar.org/eng/html/welcome.html

[15] International Atomic Energy Agency, Issues and Trends in Radioactive Waste Management, IAEA, Vienna (2003), 618 p.

[16] International Atomic Energy Agency, Protection of the Environment from Ionizing Radiation (SPEIR-3), IAEA, Vienna (2003), 432 p.

[17] International Atomic Energy Agency, Protection of the Environment from the Effects of Ionizing Radiation, IAEA-CN-109, IAEA, Vienna (to be published).

[18] International Atomic Energy Agency, Protection of the Environment from the Effects of Ionizing Radiation, IAEA-TECDOC-1091, IAEA, Vienna (1999).

[19] International Atomic Energy Agency, Ethical Considerations in Protecting the Environment from the Effects of Ionizing Radiation, IAEA-TECDOC-1270, IAEA, Vienna (2002). 